Check for updates

Cite this: RSC Adv., 2019, 9, 6438

Received 9th January 2019

Accepted 9th February 2019

DOI: 10.1039/c9ra00182d

rsc.li/rsc-advances

\section{Preparation of Ni nanoparticles by liquid-phase reduction to fabricate metal nanoparticle- polyimide composite films $\uparrow$}

\author{
Daiki Fujioka, (D) *a Shingo Ikeda, ${ }^{\mathrm{b}}$ Kensuke Akamatsu, ${ }^{\mathrm{c}}$ Hidemi Nawafune ${ }^{\mathrm{c}}$ \\ and Kazuo Kojima ${ }^{a}$
}

\begin{abstract}
Nickel-nanoparticle-containing polyimide composite films were prepared by liquid-phase reduction of $\mathrm{Ni}^{2+}$ ions with potassium borohydride $\left(\mathrm{KBH}_{4}\right)$. The nanoparticles were amorphous with diameters of approximately $10-20 \mathrm{~nm}$, depending on the $\mathrm{KBH}_{4}$ concentration and reduction temperature. At high $\mathrm{KBH}_{4}$ concentrations, the nanoparticles appeared to contain various nickel boride species. The number of nanoparticles and $\mathrm{Ni}$ content both increased upon repeated adsorption/reduction of $\mathrm{Ni}^{2+}$ ions, where the particle growth was inhibited by the rigid polymer chain and the formation of smaller particles was favored.
\end{abstract}

\section{Introduction}

Nanoparticle-containing polymer nanocomposites have recently attracted considerable attention owing to their potential applications in electronic, ${ }^{1-3}$ optical, ${ }^{4-7}$ and magnetic devices $^{8-10}$ and gas separation membranes. ${ }^{11,12}$ One crucial factor that determines the performance in such applications is the nature of the nanoparticles present in the polymer. It is also important to accurately control the nanoparticle size and interparticle distance.

Composite materials based on nanoparticles and polymers can be prepared via various methods, such as dispersing or dissolving the components in an appropriate solvent and pouring the resulting solution into a mold or onto a substrate followed by drying and solidification. ${ }^{13-15}$ However, these methods provide limited control over the spatial distribution of the particles, and close attention must also be paid to the dispersibility and solubility of the nanoparticles and polymer in the solvent. Sputtering and vacuum vapor deposition methods may also be used to introduce nanoparticles into polymer thin films synthesized by plasma polymerization, ${ }^{5}$ although these techniques require large-scale and expensive apparatuses and substantial amounts of energy, which leads to high manufacturing costs.

${ }^{a}$ Department of Applied Chemistry, College of Life Sciences, Ritsumeikan University, 1-1-1 Noji-Higashi, Kusatsu-City, Shiga 525-8577, Japan. E-mail: rc007040@ed. ritsumei.ac.jp; Tel: +81-77-561-2780

${ }^{b}$ Electronic Materials Research Division, Osaka Research Institute of Industrial Science and Technology, 1-6-50 Morinomiya, Joto-ku, Osaka 536-8553, Japan

${ }^{c}$ Department of Nanobiochemistry, Frontiers of Innovative Research in Science and Technology (FIRST), Konan University, 7-1-20 Minatojimaminami, Chuo-ku, Kobe 650-0047, Japan

$\dagger$ Electronic supplementary information (ESI) available. See DOI: 10.1039/c9ra00182d
In situ synthesis methods, in which the metal nanoparticles are precipitated inside the polymer, have also been developed. In this approach, metal ions introduced into the polymer are reduced by chemical or thermal treatment to afford metal nanoparticles. ${ }^{16-18}$ The spatial distribution of the metal nanoparticles in the composite material can be controlled by uniformly dispersing the metal ions throughout the polymer matrix $^{19-21}$ with minimal material loss and energy wastage.

Various studies on dispersing metal nanoparticles in polyimide resins have been conducted. ${ }^{\mathbf{1 9 , 2 2}}$ A method for forming highly dispersed metal nanoparticles inside a polyimide resin was proposed by the Nawafune-Akamatsu group. First, the polyimide resin was immersed in an alkaline solution to generate carboxyl groups for cation exchange, allowing a precursor resin substituted with the metal ions to be prepared. This precursor resin was then heated under a hydrogen atmosphere to reduce the metal ions. ${ }^{23,24}$

One advantage of this method is that the thickness of the surface layer formed by the nanoparticles, amount of metal ions, particle size, interparticle distance, and microstructure can be controlled via parameters such as the concentration of the alkaline solution, treatment temperature, and immersion time. Furthermore, the thermal reduction under a hydrogen atmosphere causes the polyamic acid resulting from hydrolysis of the imide rings to revert to polyimide through a dehydration reaction. Consequently, although the polyimide resin retains its physical properties, it is difficult to introduce additional metal ions to obtain new particles since the cation-exchange groups are lost during thermal reduction.

In this study, we report on the convenient preparation of a nickel nanoparticle (NiNP)-dispersed composite polymer using a high-concentration solution of potassium borohydride as the reducing agent.

The process used to prepare the NiNP-containing polymer was as follows: (1) introduction of carboxyl groups into the 
polyimide resin for cation exchange by surface modification using potassium hydroxide, (2) preparation of a precursor resin in which the cation-exchange groups were substituted with nickel ions, and (3) precipitation of the nickel by liquid-phase reduction using aqueous $\mathrm{KBH}_{4}$ solution.

We also report on the influence of the reducing agent concentration and reduction temperature on the microstructure of the metal nanoparticle-polyimide composite, and the effects of the repeated adsorption/reduction of metal ions.

\section{Experimental}

Potassium hydroxide (KOH), nickel(II) sulfate hexahydrate $\left(\mathrm{NiSO}_{4} \cdot 6 \mathrm{H}_{2} \mathrm{O}\right)$, nitric acid $\left(\mathrm{HNO}_{3}\right)$, and acetic acid $\left(\mathrm{CH}_{3} \mathrm{COOH}\right)$ were purchased from Wako Chemicals Ltd. Potassium borohydride $\left(\mathrm{KBH}_{4}\right)$ was purchased from Sigma-Aldrich Corporation. All chemicals were used as received. Pyromellitic dianhydrideoxydianiline (PMDA-ODA)-type polyimide films $(125 \mu \mathrm{m}$ thick, Nitto Denko Co., Ltd.) were used as the polymer matrix. Distilled water was used to prepare all of the aqueous solutions and in all washing processes. Polyimide nanocomposite films embedded with NiNPs were prepared using a surface modification procedure. First, polyimide films $\left(2 \times 2 \mathrm{~cm}^{2}, 125 \mu \mathrm{m}\right.$ thick) were modified by dipping in $5.0 \mathrm{~mol} \mathrm{dm}^{-3} \mathrm{KOH}$ aqueous solution at $30{ }^{\circ} \mathrm{C}$ for $5 \mathrm{~min}$, followed by thorough rinsing with copious amounts of distilled water for $5 \mathrm{~min}$. The modified films were then immersed in $0.05 \mathrm{~mol} \mathrm{dm}{ }^{-3} \mathrm{NiSO}_{4}$ aqueous solution at $30{ }^{\circ} \mathrm{C}$ for $5 \mathrm{~min}$, followed by rinsing with distilled water for $5 \mathrm{~min}$. Subsequently, the nickel-ion-doped films were immersed in aqueous $\mathrm{KBH}_{4}$ solution at $30{ }^{\circ} \mathrm{C}$ for $20 \mathrm{~min}$ to reduce the nickel ions to NiNPs. Additional reduction experiments were performed at $40{ }^{\circ} \mathrm{C}$ or $50{ }^{\circ} \mathrm{C}$. The concentration of the $\mathrm{KBH}_{4}$ solution was varied from 0.02 to $0.20 \mathrm{~mol} \mathrm{dm}^{-3}$. The polyimide nanocomposite films embedded with NiNPs were treated with $0.25 \mathrm{~mol} \mathrm{dm}{ }^{-3} \mathrm{CH}_{3} \mathrm{COOH}$ aqueous solution at $30{ }^{\circ} \mathrm{C}$ for 1 min to remove any residual adsorbed $\mathrm{Ni}^{2+}$ ions. After rinsing with distilled water for $5 \mathrm{~min}$, the films were dried with a hair dryer and stored under ambient conditions. The polyimide composite films thus obtained were annealed at $300{ }^{\circ} \mathrm{C}$ for $2 \mathrm{~h}$ under a nitrogen atmosphere.

To investigate the effect of repeated reduction on the morphology of the NiNPs, the ion adsorption/reduction treatments were repeated for three, five, or seven cycles at a temperature of $30{ }^{\circ} \mathrm{C}$.

\section{Characterization}

To quantify the amounts of nickel and boron in the prepared samples, portions of each sample were immersed in $10 \mathrm{wt} \%$ nitric acid for $20 \mathrm{~min}$ to elute the nickel and boron from the films. The nickel amounts were determined using an atomic absorption photometer (A-1000, Hitachi High-Technologies). An induction plasma emission spectrometer (ICPE-9000, Shimadzu) was used to determine the boron amounts. Changes in the chemical structure of the films were characterized using a Fourier transform infrared (FTIR) spectrometer (FT-700, Horiba) equipped with an attenuated total reflection (ATR) attachment. The crystal structure of precipitates inside the films was determined by X-ray diffraction (XRD) measurements (RINT 2000, Rigaku). The thickness of the composite layer and size of the embedded NiNPs in the films were analysed by transmission electron microscopy (TEM; JEM-2010, JEOL) operating at $200 \mathrm{kV}$. The TEM samples were prepared by sectioning into slices of $100 \mathrm{~nm}$ thickness using a conventional ultramicrotome (Ultracut EM UC7rt, Leica). The compositions of the precipitated particles were determined using energydispersive X-ray spectrometry (EDS; UTW-type detector EW$24030, \mathrm{JEOL}$ ) attached to the TEM system with an acceleration voltage of $200 \mathrm{kV}$ and a counting time of $25 \mathrm{~s}$. Elemental analysis of the films was performed using an electron beam with a diameter of $15 \mathrm{~nm}$.

\section{Results and discussion}

\section{Chemical structures of polyimide films before and after $\mathrm{KOH}$ treatment}

Fig. 1 presents the FTIR-ATR spectra of the polyimide films before and after $\mathrm{KOH}$ treatment. In Fig. 1(a), two absorption bands at 1780 and $1710 \mathrm{~cm}^{-1}$ can be observed; these correspond to the symmetric and asymmetric stretching vibrations, respectively, of the carbonyl groups of the imide ring of polyimide..$^{22,25}$

These two absorption bands are not present in Fig. 1(b). However, an absorption band at $1550 \mathrm{~cm}^{-1}$ and a broad absorption band at $1500-1700 \mathrm{~cm}^{-1}$ can be observed; the former corresponds to the $\mathrm{N}-\mathrm{H}$ bending vibration of the amide bonds formed by hydrolysis of the imide ring, while the latter is considered to originate from the stretching vibration of carboxyl groups complexed with potassium ions. This is in good agreement with a previous report, ${ }^{25}$ indicating the formation of cation-exchange groups on the film surface upon $\mathrm{KOH}$ treatment.

\section{Formation of NiNP-containing polyimide films}

Fig. S1 $\uparrow$ shows the XRD patterns of NiNP-containing polyimide (Ni-NPs/PI) films prior to annealing. No clear diffraction peaks

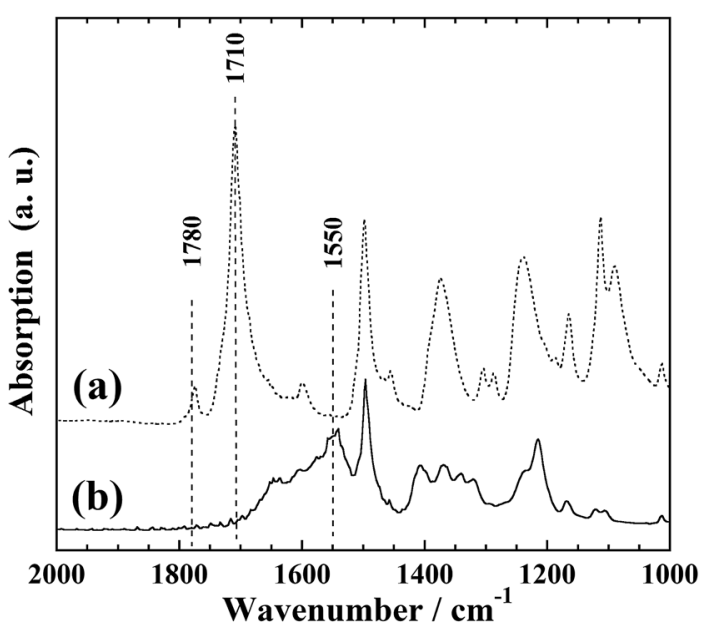

Fig. 1 FTIR-ATR spectra of polyimide films before (a) and after (b) $\mathrm{KOH}$ treatment. 
corresponding to face-centred cubic (fcc) $\mathrm{Ni}$ metal were observed, demonstrating the amorphous nature of the Ni-NPs/ PI films. After annealing the Ni-NPs/PI films at $300{ }^{\circ} \mathrm{C}$ for $2 \mathrm{~h}$ under a nitrogen atmosphere, the XRD patterns contained two peaks corresponding to fcc $\mathrm{Ni}$ metal at $2 \theta=44.5^{\circ}$ and $51.8^{\circ}$, confirming the presence of crystalline nickel metal (Fig. 2). Sample (A) is a film with metallic lustre and shows conductivity; therefore, Ni metal is considered to get deposited in a film form.

The nickel ions formed metallic clusters that afforded a weak peak on the high-angle side of the XRD patterns.

Fig. 3 shows the results of quantitative analysis of nickel and boron ions in the samples after the $\mathrm{Ni}^{2+}$ reduction treatment. It

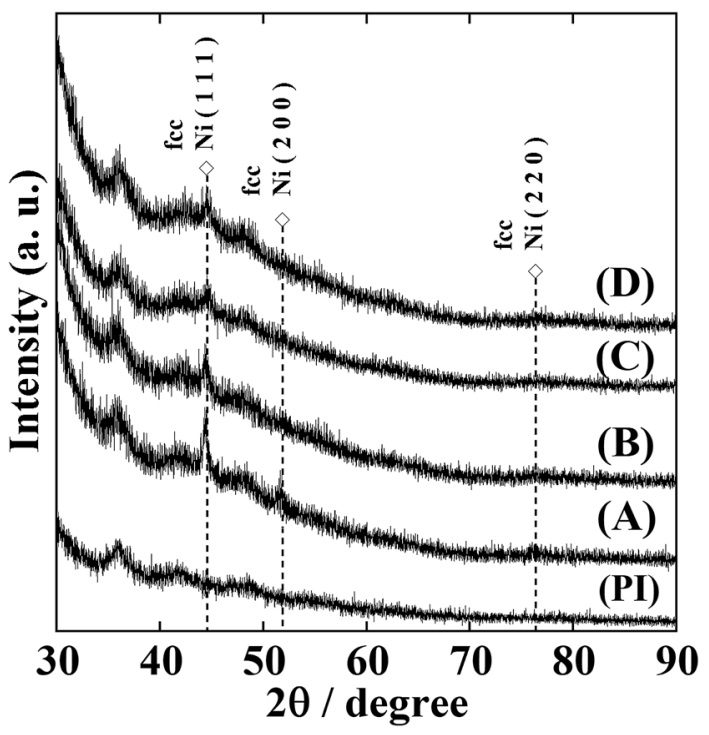

Fig. 2 XRD patterns of the Ni-NPs/PI films with being annealed at $300{ }^{\circ} \mathrm{C}$ for $2 \mathrm{~h}$ in a nitrogen atmosphere. The films were prepared by immersed polyimide film containing $\mathrm{Ni}^{2+}$ ions into $\mathrm{KBH}_{4}$ aqueous solutions of (A) 0.02 , (B) 0.06 , (C) 0.12 , and (D) $0.20 \mathrm{~mol} \mathrm{dm}^{-3}$. A polyimide film without embedded nickel ions (PI) shows no nickel diffraction patterns.

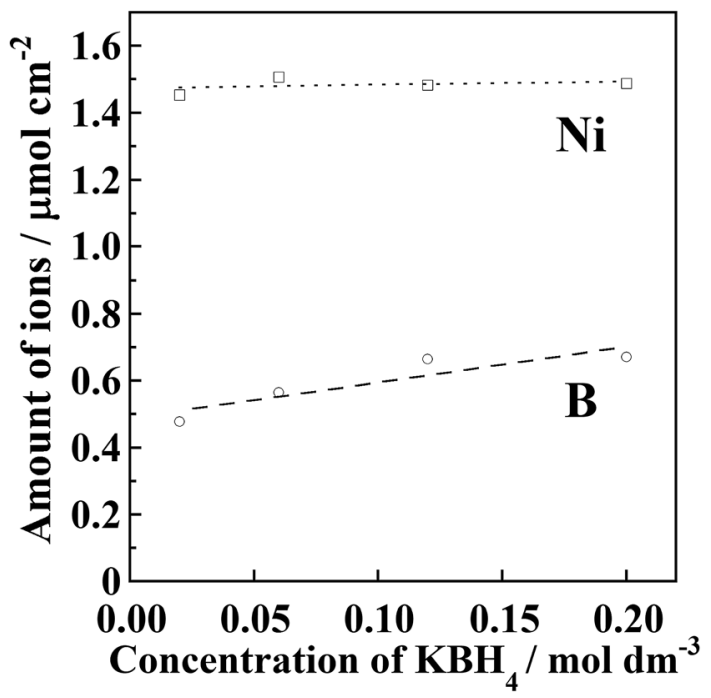

Fig. 3 Amounts of $\mathrm{Ni}$ and boron ions in Ni-NPs/PI films. was found that the amount of deposited $\mathrm{Ni}$ did not change although the reducing agent concentration was different. The average $\mathrm{Ni}$ content in the precursor films after the introduction of $\mathrm{Ni}^{2+}$ ions was $1.48 \mu \mathrm{mol} \mathrm{cm} \mathrm{cm}^{-2}$. Residual $\mathrm{Ni}^{2+}$ ions inside the resin were removed by immersing the film in aqueous $\mathrm{CH}_{3}$ $\mathrm{COOH}$ solution. In other words, if unreduced $\mathrm{Ni}^{2+}$ ions were present, the amount of deposited Ni should be lower than the initially introduced amount. Therefore, it is considered that all of the introduced $\mathrm{Ni}^{2+}$ ions were deposited as metallic nickel inside the polyimide resin.

The boron content in the samples was found to increase with increasing reducing agent concentration. Assuming that all of the boron atoms were mixed with the deposited nickel atoms, 6-8 wt\% of boron should be contained in the deposited nickel. It has been reported that metallic nickel films produced by electroless plating are amorphous when the boron content exceeds approximately $3 \mathrm{wt} \% .^{26-30}$ It has also been reported that $\mathrm{Ni}$ nanoparticles become amorphous when phosphorus ${ }^{31-33}$ or boron $^{34-38}$ is contained in the nanoparticles. Furthermore, when boron-containing nickel films are heated at $300-400{ }^{\circ} \mathrm{C}$, nickel borides are formed. As shown in Fig. 2, no diffraction patterns corresponding to nickel borides were observed for the samples annealed at $300{ }^{\circ} \mathrm{C}$. Therefore, it is considered that the detected boron content originated not from the deposited nickel but from reducing agent residue inside the modified layer.

Fig. 4 shows the cross-sectional TEM images, electron diffraction patterns, and Ni particle size distributions of the $\mathrm{Ni}$ NPs/PI films prior to annealing. The electron diffraction patterns show halo patterns. This is the same tendency as the result shown by the XRD patterns in Fig. S1. $\dagger$ The nanoparticles are amorphous. The particle size distributions were obtained by counting the particles in the area $\left(600 \times 450 \mathrm{~nm}^{2}\right)$ shown in Fig. 4 . The mean diameters of the nanoparticles in the samples
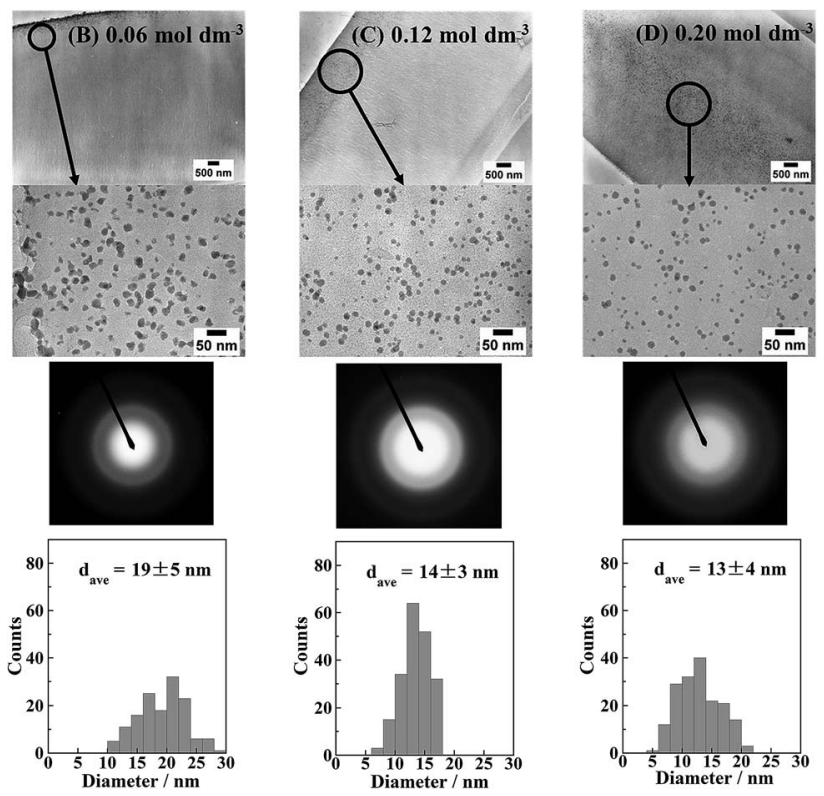

Fig. 4 Cross-sectional TEM images and electron diffraction patterns of the Ni-NPs/PI films (B)-(D) shown in Fig. S1.† Particle size distributions of Ni nanoparticles are also shown. 
reduced with $0.06,0.12$, and $0.20 \mathrm{~mol} \mathrm{dm}^{-3} \mathrm{KBH}_{4}$ solutions were $19 \pm 5,14 \pm 3$, and $13 \pm 4 \mathrm{~nm}$, respectively. Therefore, the average particle size decreased with increasing $\mathrm{KBH}_{4}$ concentration. This is because nucleation predominates over nucleus growth and the rate of nucleation would be expected to increase with increasing $\mathrm{KBH}_{4}$ concentration. In general, particle deposition begins with a nucleus that initially acts as a seed for the growing particle before increasing in size. However, at low $\mathrm{KBH}_{4}$ concentrations, the $\mathrm{BH}_{4}{ }^{-}$ion does not diffuse deeply into the resin. Therefore, particle nucleation preferentially occurs near the resin surface where the reducing agent can penetrate. It is considered that this nucleus acts as a reduction centre to which $\mathrm{Ni}^{2+}$ ions diffuse, resulting in the growth of $\mathrm{Ni}$ particles. As the $\mathrm{KBH}_{4}$ concentration increases, the reducing agent can penetrate deeper into the reformed layer, such that the nucleus precipitates inside the reformed resin layer.

In addition, when the nucleation rate is higher, nucleation prevails over nanoparticle growth. Although the amount of $\mathrm{Ni}$ ions initially introduced was the same, the Ni was preferentially consumed for nucleation, and thus nanoparticle growth was suppressed. Therefore, the particle size decreased with increasing reducing agent concentration.

Fig. 5 shows the cross-sectional TEM images and EDS elemental analysis results for the Ni-NPs/PI films prior to annealing. The EDS elemental analysis of Ni was performed during TEM observation using a $15 \mathrm{~nm}$ electron beam and the same measurement time (25 s). The EDS spectra revealed a higher Ni abundance for the nanoparticles compared with the area lacking nanoparticles. No lattice images of nanoparticles were observed in high-resolution TEM images. An FFT image of the particle a supports this result. Therefore, based on the XRD, EDS, and high-resolution TEM results, the formed nanoparticles are considered to be composed of amorphous $\mathrm{Ni}$ metal. Moreover, small amounts of $\mathrm{Ni}$ were detected in the area of the resin surrounding the particles, possibly indicating $\mathrm{Ni}$ clusters that could not be observed by TEM.

Nanoparticles with an average size of 3-12 $\mathrm{nm}$ were observed in the samples reduced at temperatures of 30,40 , and $50{ }^{\circ} \mathrm{C}$.
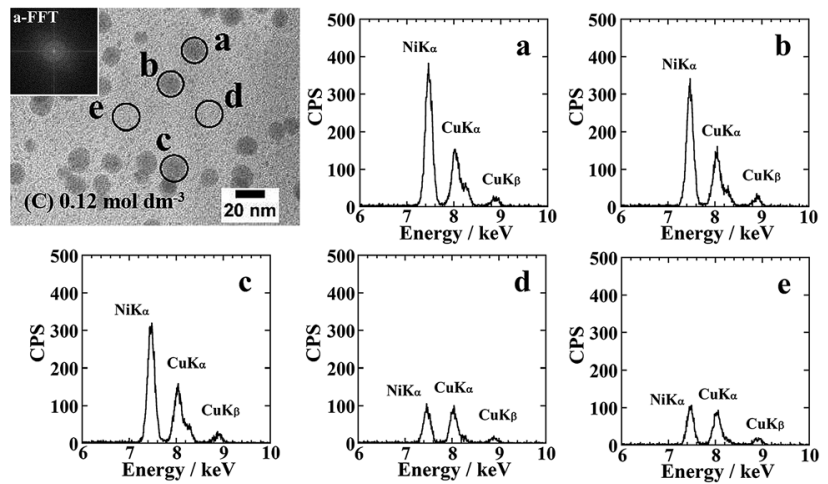

Fig. 5 Results of EDS elemental analysis for the Ni-NPs/PI film (C) shown in Fig. 4. The spectra (a-e) were obtained from the area in high resolution TEM images (black circle a-e). Analysis was performed with a $10 \mathrm{~nm}$ electron beam spot for the detectable particles $(a, b$, and $c)$ and for the area between the particles ( $d$ and e). The insertion in the TEM photograph is an FFT image of the particle a.
Fig. S2 $\uparrow$ shows cross-sectional TEM image and particle size distributions of a Ni-NPs/PI film reduced at $50{ }^{\circ} \mathrm{C}$. The electron diffraction and EDS results revealed that the formed NiNPs consisted of metallic nickel with an fcc structure. The average particle size of the nanoparticles in the sample reduced at $30{ }^{\circ} \mathrm{C}$ was $11 \mathrm{~nm}$, and smaller particles with a size of approximately $4 \mathrm{~nm}$ were also formed in the samples reduced at 40 and $50{ }^{\circ} \mathrm{C}$. The number of these smaller particles increased with increasing reduction temperature, and the number of particles around $10 \mathrm{~nm}$ also increased and their sizes tended to decrease. Therefore, a low reduction temperature promoted nucleus growth, resulting in increased particle size. Conversely, a high temperature increased the rate of the reduction reaction and led to faster nucleation, thereby increasing nucleation progresses relative to nucleus growth and leading to an increased number of particles and decreased particle size.

\section{Effect of repeated adsorption/reduction treatment}

Fig. $\mathrm{S} 3 \uparrow$ shows XRD patterns of samples subjected to repeated adsorption/reduction of $\mathrm{Ni}^{2+}$ ions. No diffraction patterns attributable to metallic nickel were observed, indicating that the deposited nickel was in an amorphous or quite fine crystallite state.

Fig. 6 shows that the Ni content increased with an increasing number of adsorption/reduction cycles, confirming the feasibility of increasing the amount of $\mathrm{Ni}$ in the polyimide resin by repeated adsorption/reduction treatment.

Fig. S4 $\uparrow$ shows cross-sectional TEM images of the samples subjected to repeated adsorption/reduction of $\mathrm{Ni}^{2+}$ ions. The formation of nanoparticles with an average particle size of 10$30 \mathrm{~nm}$ was confirmed in all of the samples. The surfaces of the resins subjected to three, five, and seven adsorption/reduction cycles were not covered with films, but were instead occupied by a large amount of deposited nanoparticles. In addition, the

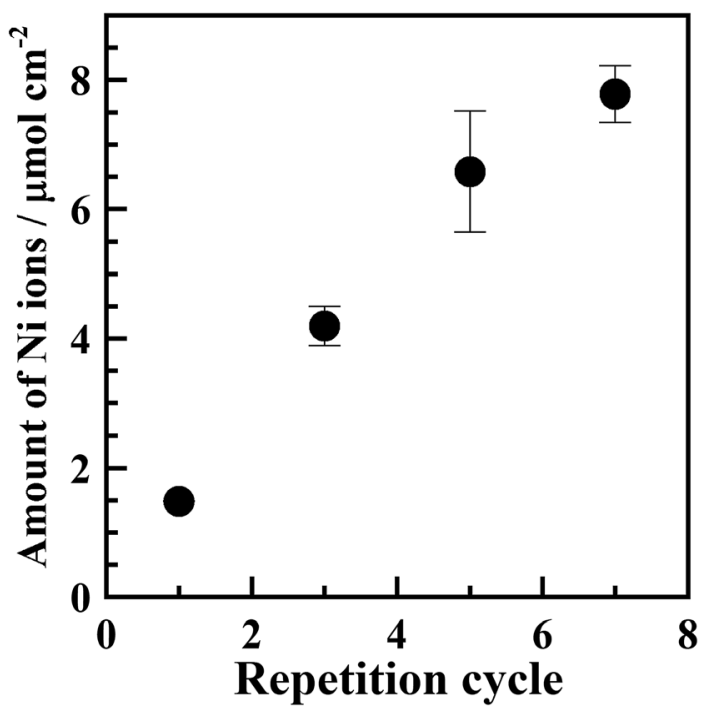

Fig. 6 Amounts of $\mathrm{Ni}$ ions in the samples reduced with $0.20 \mathrm{~mol} \mathrm{dm}^{-3}$ $\mathrm{KBH}_{4}$ aqueous solution at $30{ }^{\circ} \mathrm{C}$ and subjected repeatedly to adsorption/reduction treatment. The amounts per unit film area were determined using an atomic absorption photometer. 
particles were dispersed throughout the reformed layer, and tended to be deposited in the deepest part of the reformed layer. Furthermore, comparison of the samples subjected to three, five, and seven adsorption/reduction cycles revealed that large particles were dispersed throughout the entire reformed layer in the sample subjected to seven cycles.

As shown by the particle size distributions in Fig. $\mathrm{S} 4, \uparrow$ the average particle size was approximately $28 \mathrm{~nm}$ for the three samples. To obtain these distributions, all of the particles in the entire region $\left(1.6 \times 1.2 \mu \mathrm{m}^{2}\right)$ of the TEM images were counted. This average particle size of $28 \mathrm{~nm}$ is more than double that observed for the sample subjected to a single adsorption/ reduction cycle. Furthermore, increasing the number of cycles from three to seven had little effect on the number of particles with a size of $30 \mathrm{~nm}$ or more and no change in the total number of particles was observed. This finding seems to contradict the results shown in Fig. 6, where the $\mathrm{Ni}$ content was found to increase with an increasing number of cycles. This suggests that an increased number of cycles resulted in an increased number of particles with diameters smaller than those shown in Fig. S4. $\dagger$

Fig. 7 shows high-resolution cross-sectional TEM images and the number of particles per unit area for the samples subjected to repeated adsorption/reduction of $\mathrm{Ni}^{2+}$ ions; the arrows in Fig. 7(a)-(c) indicate the presence of numerous particles with sizes of several nanometers or less. However, since these particles are small in size and located inside the resin, the contrast of the particle image is not clear. Since it was difficult to precisely specify the particle size, the number of identified particles was counted in the whole region $\left(250 \times 150 \mathrm{~nm}^{2}\right)$ shown in the enlarged view. The number of particles per unit area is shown in Fig. 7(b). The results revealed that the number of particles increased with an increasing number of cycles. This is consistent with the tendency shown in Fig. 6 for the amount of Ni. It is presumed that the rigid polymer network inhibited
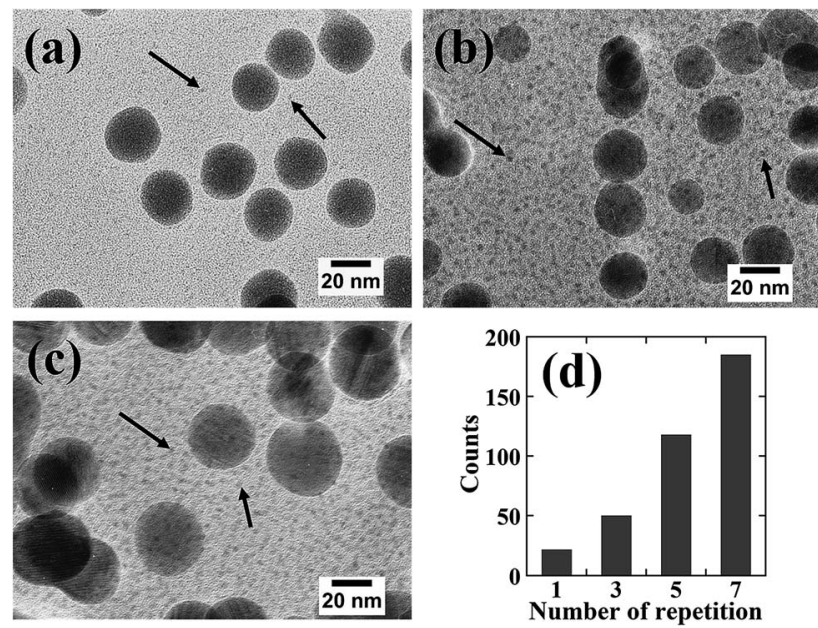

Fig. 7 High resolution cross sectional TEM images of the samples prepared by repeated $\mathrm{Ni}^{2+}$ ion adsorption/reduction treatments with for (a) three, (b) five, and (c) seven cycles. The counts in (d) were obtained for each area of $250 \times 150 \mathrm{~nm}^{2}$ in (a)-(c). The counts for one repetition number in (d) were obtained from the particle size distribution for an area of $250 \times 150 \mathrm{~nm}^{2}$ in the area d in Fig. 5 . the growth of particles with sizes of $30 \mathrm{~nm}$ or greater; therefore, the number of large particles remained approximately constant while the number of small particles increased.

Fig. S5† presents electron diffraction patterns of the samples. The sample subjected to three adsorption/reduction cycles exhibited a halo pattern, whereas the samples subjected to five or seven cycles afforded spot-like diffraction images similar to the image observed for the polycrystalline phase. However, it was difficult to interpret the diffraction images owing to the large number of spots present. Based on the ICDD data, the XRD patterns of $\mathrm{Ni}$ with the fcc structure, $\mathrm{NiB}, \mathrm{Ni}_{2} \mathrm{~B}$, and $\mathrm{Ni}_{3} \mathrm{~B}$ were compared, as shown in Fig. S6. $\uparrow$ Numerous peaks corresponding to nickel borides were observed on both the lowand high-diffraction-angle sides of the $\mathrm{Ni}(111)$ and $\mathrm{Ni}(200)$ peaks. As shown in Fig. S5(c) and (d), $\dagger$ diffraction spots were also observed at positions closer to the $\mathrm{Ni}(111)$ and $\mathrm{Ni}(200)$ planes of fcc Ni. The above results indicate that nickel boride nanoparticles were present in parts of the deposited material. The formation of nickel borides with high crystallinity is probably attributable to the facile incorporation of boron atoms into the precipitates upon prolonged exposure to high concentrations of $\mathrm{KBH}_{4}$.

\section{Conclusions}

Liquid-phase reduction of $\mathrm{Ni}^{2+}$ ions in polyimide films was found to result in the precipitation of $\mathrm{Ni}$ in the form of a film on the surface of the resin or nanoparticles inside the resin, depending on the reducing agent concentration. At low reducing agent concentrations, NiNPs with an average particle size of 10-20 nm were formed inside the resin. As the reducing agent concentration was increased, the particles became more deeply dispersed in the modified layer and the average particle size tended to decrease. From the results of no lattice fringes observed in the high-resolution TEM images, electron diffraction patterns, and EDS analysis, it is highly probable that the formed NiNPs were amorphous metallic Ni. Nickel was also detected in the resin surrounding the particles, which was ascribed to the presence of Ni clusters not visible by TEM. Regarding particle precipitation, as the reducing agent concentration was increased, the precipitated particles displayed a tendency to spread inside the modified resin layer, and a tendency toward a smaller average particle size was also observed.

Nanoparticles with an average size of 3-12 $\mathrm{nm}$ were formed in the samples reduced at temperatures of 30,40 , or $50{ }^{\circ} \mathrm{C}$. The number of these small particles increased with increasing temperature, and the number of particles around $10 \mathrm{~nm}$ also increased and their sizes tended to decrease. Higher temperatures led to an increased nucleation rate and favoured nucleation rather than nucleus growth, resulting in an increased number of particles and decreased particle size.

Samples subjected to three, five, or seven adsorption/ reduction cycles were found to possess an average particle size of approximately $28 \mathrm{~nm}$. The surfaces of the resins subjected to these adsorption/reduction cycles were not covered with films, but were instead occupied by a large amount of 
deposited nanoparticles. The number of particles increased with an increasing number of cycles. This is consistent with the tendency observed for the $\mathrm{Ni}$ content with an increasing number of cycles. It is considered that the rigid polymer network inhibited the growth of particles with sizes of $30 \mathrm{~nm}$ or greater, causing the number of large particles to remain approximately constant while the number of smaller particles increased. It was therefore possible to increase both the number of particles and Ni content by performing repeated adsorption/ reduction cycles. Electron diffraction results and ICDD data indicated that nickel boride nanoparticles with high crystallinity were present in parts of the deposited material. The formation of these nickel borides is probably attributable to the facile incorporation of boron atoms into the precipitates upon prolonged exposure to high concentrations of $\mathrm{KBH}_{4}$.

\section{Conflicts of interest}

There are no conflicts to declare.

\section{Acknowledgements}

The authors thank the late Dr Masao Matsuoka for his eager direction and encouragement.

\section{Notes and references}

1 C. L. Tsai, H. J. Yen and G. S. Liou, React. Funct. Polym., 2016, 108, 2-30.

2 F.-Y. Shen, S.-E. Huang and W.-P. Dow, ECS Electrochem. Lett., 2013, 2, 45-48.

3 T. W. Kim, J. H. Jung, C. S. Yoon and Y. H. Kim, Appl. Phys. Lett., 2008, 92, 042103.

4 R. Singh and S. Prakash, Surf. Sci., 2003, 532-535, 272-275.

5 D. Salz, B. Mahltig, A. Baalmann, M. Wark and N. Jaeger, Phys. Chem. Chem. Phys., 2000, 2, 3105-3110.

6 C. W. Hsu, B. Zhen, W. Qiu, O. Shapira, B. G. DeLacy, J. D. Joannopoulos and M. Soljačić, Nat. Commun., 2014, 5, 1-6.

7 H. Choi, S.-J. Ko, Y. Choi, P. Joo, T. Kim, B. R. Lee, J.-W. Jung, H. J. Choi, M. Cha, J.-R. Jeong, I.-W. Hwang, M. H. Song, B.-S. Kim and J. Y. Kim, Nat. Photonics, 2013, 7, 732-738.

8 I. Toda, T. Tsuruoka, J. Matsui, T. Murashima, H. Nawafune and K. Akamatsu, RSC Adv., 2014, 4, 4723-4726.

9 S. Tomita, P. E. Jönsson, K. Akamatsu, H. Nawafune and H. Takayama, Phys. Rev. B, 2007, 76, 174432.

10 J. H. Kim and C. S. Yoon, Thin Solid Films, 2008, 516, 48454850.

11 S. Hasebe, S. Aoyama, M. Tanaka and H. Kawakami, J. Membr. Sci., 2017, 536, 148-155.

12 E. P. Favvas, F. K. Katsaros, S. K. Papageorgiou, A. A. Sapalidis and A. C. Mitropoulos, React. Funct. Polym., 2017, 120, 104-130.

13 Y. J. Cheng, S. Renker, Z. Sun and J. S. Gutmann, Macromol. Rapid Commun., 2005, 26, 613-619.
14 Y. Dirix, C. Bastiaansen, W. Caseri and P. Smith, J. Mater. Sci., 1999, 34, 3859-3866.

15 V. Zaporojtchenko, J. Zekonyte, A. Biswas and F. Faupel, Surf. Sci., 2003, 532-535, 300-305.

16 S. Clémenson, D. Léonard, D. Sage, L. David and E. Espuche, J. Polym. Sci., Part A: Polym. Chem., 2008, 46, 2062-2071.

17 T. Del Castillo-Castro, E. Larios-Rodriguez, Z. MolinaArenas, M. M. Castillo-Ortega and J. Tanori, Composites, Part A, 2007, 38, 107-113.

18 T. C. Wang, M. F. Rubner and R. E. Cohen, Langmuir, 2002, 18, 3370-3375.

19 S. Ikeda, K. Akamatsu, H. Nawafune, T. Nishino and S. Deki, J. Phys. Chem. B, 2004, 108, 15599-15607.

20 K. Akamatsu, S. Adachi, T. Tsuruoka, S. Ikeda, S. Tomita and H. Nawafune, Chem. Mater., 2008, 20, 3042-3047.

21 K. Akamatsu, S. Ikeda and H. Nawafune, Langmuir, 2003, 19, 10366-10371.

22 Y.-S. Hsiao, W.-T. Whang, S.-C. Wu and K.-R. Chuang, Thin Solid Films, 2008, 516, 4258-4266.

23 K. Akamatsu, K. Nakahashi, S. Ikeda and H. Nawafune, Eur. Phys. J. D, 2003, 24, 377-380.

24 K. Akamatsu, S. Ikeda, H. Nawafune and S. Deki, Chem. Mater., 2003, 15, 2488-2491.

25 R. R. Thomas, S. L. Buchwalter, L. P. Buchwalter and T. H. Chao, Macromolecules, 1992, 25, 4559-4568.

26 P. S. Kumar and P. K. Nair, Nanostruct. Mater., 1994, 4, 183198.

27 V. Vitry and L. Bonin, Surf. Coat. Technol., 2017, 311, 164171.

28 V. Vitry, A. F. Kanta, J. Dille and F. Delaunois, Surf. Coat. Technol., 2012, 206, 3444-3449.

29 K. Krishnaveni, T. S. N. Sankara Narayanan and S. K. Seshadri, Surf. Coat. Technol., 2005, 190, 115-121.

30 A. F. Kanta, V. Vitry and F. Delaunois, Mater. Lett., 2009, 63, 2662-2665.

31 K. Mandel, F. Dillon, A. A. Koos, Z. Aslam, K. Jurkschat, F. Cullen, A. Crossley, H. Bishop, K. Moh, C. Cavelius, E. Arzt and N. Grobert, Chem. Commun., 2011, 47, 4108-4110.

32 J. Wang, A. C. Johnston-Peck and J. B. Tracy, Chem. Mater., 2009, 21, 4462-4467.

33 S. Xie, M. Qiao, W. Zhou, G. Luo, H. He, K. Fan, T. Zhao and W. Yuan, J. Phys. Chem. B, 2005, 109, 24361-24368.

34 J. Guo, Y. Hou, B. Li and E. Duan, Mater. Lett., 2017, 200, 9093.

35 J. Shao, X. Xiao, X. Fan, L. Chen, H. Zhu, S. Yu, Z. Gong, S. Li, H. Ge and Q. Wang, Mater. Lett., 2013, 109, 203-206.

36 Z. Wu, M. Zhang, Z. Zhao, W. Li and K. Tao, J. Catal., 2008, 256, 323-330.

37 F. Wu, Z. Zhang, F. Zhang, D. Duan, Y. Li, G. Wei, S. Liu, Q. Yuan, E. Wang and X. Hao, Electrochim. Acta, 2018, 287, 115-123.

38 Z. L. Schaefer, X. Ke, P. Schiffer and R. E. Schaak, J. Phys. Chem. C, 2008, 112, 19846-19851. 